\title{
The Application and Research of Property-management Information System based on JSF Technology
}

\author{
Lin Tang \\ School of Information Engineering, Chongqing Vocational Institute of Engineering, Chongqing, \\ 402260, China
}

lintang2012@yeah.net

Keyword: Property management; JSF; feasibility analysis

\begin{abstract}
With the rapid social development, the traditional property management model has become increasingly unable to meet the needs of the owners on property management. This paper mainly discusses the development process of residential property-management information system. Firstly it analyzes the development and the usage status of domestic property-management information system, and points out the existing problems in the present usage process; then according to the basic requirement of modern society on residential management, and conducts the feasibility analysis and the overall design and realization of the system by using JSF. This system includes residential information module, staff information module, property module and authorization module. It has established the development direction for the modernized intelligent residential property management.
\end{abstract}

\section{Introduction}

With the rapid development of social economy and the increasing improvement of living levels, people enhance their demand for family life tastes ands level unceasingly and also their enthusiasms for the real estate investment. Now, people not only put forward higher requirements for the beauty of their own houses and the reasonability of the layouts and decorations inside their families; at the same time put forward higher and higher requirements for community service and management; with the enhancement of social sense of ownership and responsibility for the society, people also more concern and participate in the residential daily management and major policy-decisions. For example, the residential repairs, maintenance of green fields, settings of fitness equipment and so on require the residential managers to carry out meticulous management in the macro and micro aspects on the property. In order to realize these objective demands and cater to this inner development trend, the level of residential property services shall be improved. These objective factors provide the necessary market need for designing residential property management system [1].

Traditional property management in 1960s in the United Kingdom creates the necessary conditions for the development of the property management system with the popularization and the rapid development of computer technology [2]. In 1980s, the application of computer monitoring and control system makes an old building in Hartford, Kangnai Niege state of America become the focus of people's attention. Among them, not only air-conditioners, elevator, lighting and other equipment are altered and upgraded, but information services including language communication, word processing and email are also provided for users [3]. In recent years, China's real estate industry rapidly develops, and all kinds of commercial buildings, office buildings, residential quarters, writing buildings, hotels and others rapidly rise [4]. The development of the real estate industry promotes the birth of the property management. Property management is an activity of the people to implement the maintenance and management of housing, public facilities, utilities and related fields. The reason for it to become a kind of specialized, socialized industry lies in the formation of modern city and the development of city real estate [5].

In 2001 May, ED Burns, Craig R and McClannahan et al proposed the intention of JSF, and in 2004 May finally formed the JSF specifications, which mainly includes two aspects: one is the API 
collection, which is used to represent the users' interface components; the other is a JSP custom tag library. This paper uses the JSF technology design to implement the property management information system.

\section{The System Analysis}

The requirement analysis. According to the research results, property management system of the Garden District in Xianyang city includes the following functions mainly: permissions settings, data management, repair management, cost management, equipment management, and the auxiliary data-statistics function.

(1) The permission settings for users

The users in the system are divided into two categories: administrators, ordinary users. The function of the administrator is to maintain the system, including data backup, export and import, and also to carry on the management on users in the system according to needs. Ordinary users can only in the permissions allowed range, basic operation of system, for example: query, add, and browse the community information, household information, equipment information, the warranty information, and complaint information, etc. In addition, ordinary users can only modify their own information, but the administrator can modify the information for all personnel.

(2)Residential information management

Residential information includes parking areas, accommodation buildings, fitness facilities, fire equipment, so residential information management includes the increase, deletion, change, search and other basic operations on the above information.

(3) Personnel information management

It can register, query, modify the management personnel (and common users), and in addition, it also includes the establishment of the corresponding files for residents to achieve the timely management of personnel.

(4) The maintenance of information management

The maintenance of information management includes two parts: the view collections and complaint management of households on residential construction, and the various repair information etc. of households during the residential construction. This module realizes the query, browsing and other operations on the above information.

(5) The charge for information management

This module mainly realizes the management of costs such as household property costs, utilities, and other costs such as cleaning.

\section{The Feasibility Study}

The technical feasibility; Technical feasibility refers to the realization of the system function in a predetermined and expected period of time through corresponding computers' technical means. JSF is a UI component and Web application framework based on Java, which also supports the simple IOC (Inversion of Control) and value and method references, also with very strong expansibility, focusing on the creation and management of the user interfaces [6]. It supplements with Servlet, JSP and other technologies mutually. Servlet is the basis of JSF, which defines how to use the server components to encapsulate and realize Web applications, while JSP provides a mechanism of a page template to create text content based on the Servlet, which can be integrated with JSF very well. The standard tag library (JSTL) defines a standard set of JSP operations, and simplifies thepage development, which can complement with the JSF tag library mutually [7]. Therefore, the project is feasible in the technology.

The economic feasibility; The economic feasibility of the software refers to the evaluation of all the costs needing for expenditure based on full consideration of the project, including labor costs, management fees, equipment procurement costs and maintenance costs, etc. While the software income mainly includes indirect benefits brought by this software, including the saved cost by reducing staff etc. The existing property management adopts the artificial method, and currently the 
residential is divided into three districts of $\mathrm{A}, \mathrm{B}, \mathrm{C}$, with 9 imports and exports in total and 18 duty staff. Each partition sets 1 property service station. Each service station has 1 webmaster, 2 attendants, 1 hydropower engineering. 1, and 2 greening staff, and 16 cleaning staff for 32 residential buildings, and 12 duty personnel in total for 6 car garages, and 3 district patrols, with 10 members in each, which are divided into two shifts. Thus the staff only maintaining basic service personnel reach 84, and only the monthly wage costs reach more than 240,000 Yuan.

\section{The System Design}

The flow chart is also called the transaction flow diagram, which is a commonly used description method to analyze the system in treating and applying computer affairs, and also a weapon to analyze the system function and operate procedures. It uses abstract graphs to describe the data flow among the various sub modules of the system, describing the logical process for each treating processes from data obtained input to output gained in treating affairs. This paper uses the flow chart to describe the business process of the information management module and the property management.

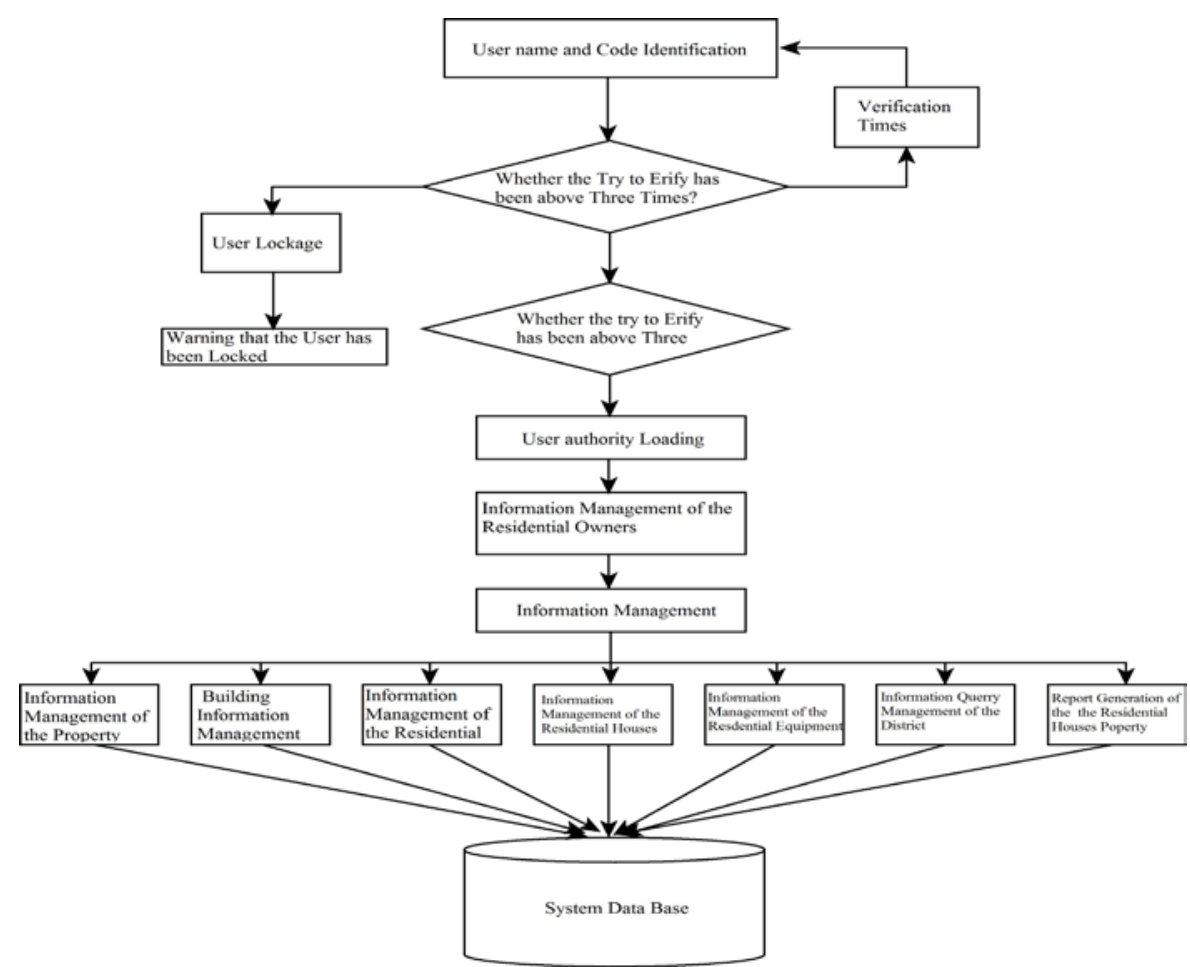

Figure 1. The flow chart of the system

Data dictionary generally includes the data items, data flows, data structures and data storage, and the treating processes of data. It can describe the logic content of data flow and data storage according to the definitions of the data items and data structure [8].

\begin{tabular}{|c|c|c|c|c|c|c|}
\hline No. & Data Item & Illustrations & Name & Length & Value Connotations & Logic Relations \\
\hline 1 & personID & Resident Marks & Resident No & 18 & ID. Card No & $\begin{array}{l}\text { Key Buttoon, Determined by the Other } \\
\text { Data ltems of the Residents }\end{array}$ \\
\hline 2 & facilityID & Construction Marks & Construction No & 5 & Two Residential No. + Three Ordering No. & $\begin{array}{l}\text { Key Buttoon, Determined by the Other } \\
\text { Data items of the Equipment }\end{array}$ \\
\hline 3 & chargesID & Fee List Marks & Fee List No & 11 & No & $\begin{array}{l}\text { Key Buttoon, Determined by the } \\
\text { Other Data liems of the Fee List }\end{array}$ \\
\hline 4 & buildingID & Building Marks & Building No & 6 & Unit No++Buildings+ Two ordering No & $\begin{array}{l}\text { Key Buttoon, Determined by the Other } \\
\text { Data Items of the Building }\end{array}$ \\
\hline 5 & parkID & Parking Marks & Parking No & 5 & Two residential $\mathrm{No}$. + Three ordering No & $\begin{array}{l}\text { Key Buttoon, Determined by the other } \\
\text { Data ltems of the Park }\end{array}$ \\
\hline 6 & guiderID & Staff Marks & Staff No & 18 & ID. Card No & $\begin{array}{l}\text { Key Buttoon, Determined by the other } \\
\text { Data liems of the Staff }\end{array}$ \\
\hline
\end{tabular}

Figure 2 The data dictionary of the system 


\section{The System Implementation}

Figure 3 is the system main interface seen after successful logging in the system, and the design of the main interface is mainly to enable users to carry out personal daily operations very conveniently, view the meeting, notices, news, work schedules, and the newest owners' complaints or related applications. The main interface is composed of the upper, left, middle-three frame parts. The upper frame displays the interface time, the login, personal settings, to-do lists etc.. The left frame mainly sets the main operation module of the property management system (19 in total), which can expand the next-level operation sub-module after clicking (sub-modules vary according to the property process of management and the content and number), which is convenient for users to carry out related operation links. The middle frame displays main operation contents for module functions, which is the theme part of the entire page, and has different display and operation functions according to the different operation contents. The system main interface is as shown in figure 1.

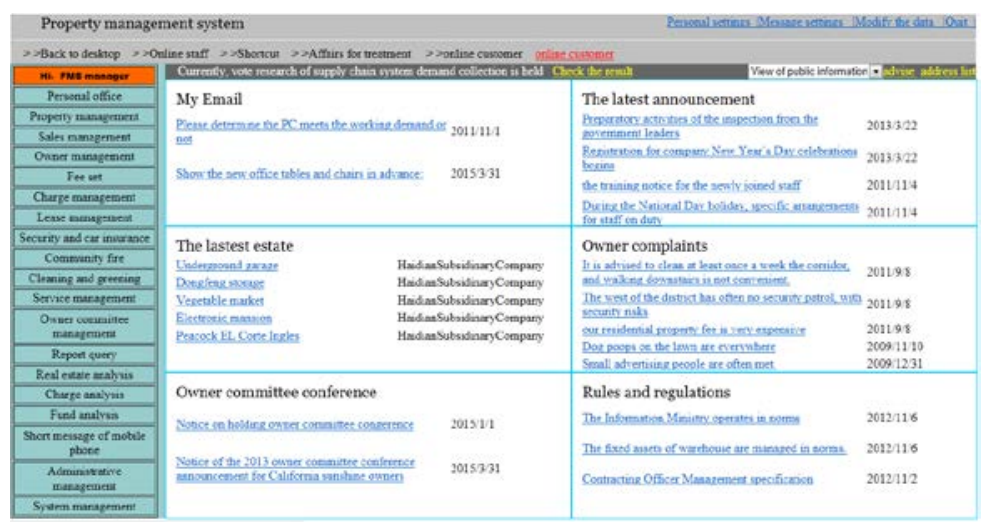

Fig. 3 The system main interface

The owners' management sub-module can realize the function such as the increase, deletion, change and check of owners' basic data. The added page of owners' information as shown in figure 4 can be entered after clicking the menu on the left of the option "the added owners information" under the sub-module "owner management"' in the left menu. Among them, the basic information for the owner can be added (including the types of owners, house number, the unit, address, telephone and other content), and after clicking "OK", the system will automatically save the input information into the database; when modification is required, you can directly click the option " the added owners information" to carry out the modification operation on the relevant contents.

\begin{tabular}{|c|c|c|c|c|}
\hline \multicolumn{2}{|c|}{ New owner Information } & \multicolumn{2}{|l|}{ Sales Contact No } & \multirow{2}{*}{\begin{tabular}{|l|l|} 
extract \\
$\nabla$
\end{tabular}} \\
\hline Company: & $\nabla *$ & Owner type: & \begin{tabular}{|l} 
Official owner \\
\end{tabular} & \\
\hline Owner No.: & ]* & Owner name: & & ]* \\
\hline Gender: & Male & Birth date: & & 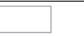 \\
\hline Nation : & $\square$ & \begin{tabular}{|l} 
Education \\
background:
\end{tabular} & & $\nabla$ \\
\hline Nationality : & $\square$ & Native place: & & ] \\
\hline ID. Type: & $\nabla *$ & ID. No.: & & * \\
\hline Work unit : & 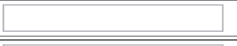 & Occupation: & & \\
\hline Phone No.: & * & Postal code: & & \\
\hline \multicolumn{5}{|l|}{ Contact address : } \\
\hline $\begin{array}{l}\text { Emergency contact } \\
\text { people : }\end{array}$ & & Emergency phone: & & \\
\hline \multicolumn{5}{|l|}{ Emergency address : } \\
\hline Account : & & Account No.: & & 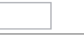 \\
\hline $\begin{array}{l}\text { The local police } \\
\text { station }\end{array}$ & $\square$ & State & Normal & $\nabla$ \\
\hline
\end{tabular}

Fig.4. the owner-management module

The residential information management includes the function management such as the increase, deletion, and change, search of the basic information such as residential buildings, parking areas and facilities. 
Household cost query. This module realizes the search function of generated information costs in the accommodation process. According to the authority, managers can modify, delete the cost, but the ordinary users can only query the basic situation of some expenses produced by them, and can not carry out other operations such as deletion, modification on the list.

\section{Conclusions}

This paper studies the intelligent residential property-information management system, which meets the requirements of comprehensiveness and advancement and meets the requirements of the daily management work, and can realize the automatic collection and processing ability on data to make the management process to achieve the detailed and in-depth level. This system achieves the integrated management monitoring and monitoring under the unified interface and integrates the information analysis and property management services into one. It reduces the labor intensity of management and achieves the management efficiency through the implemented full management of staff, equipment, goods, services, information, finance and all activities and gives full play in assisting decision-making.

\section{Acknowledgments}

The work was supported by the science and technology research projects of Chongqing Education Commission with its project number KJ132001 and its project name Research on Fixed Assets Management System Based on Internet of Things.

\section{References}

[1] Master thesis. Dalian: Dalian University of Technology, 2009.

[2] Wang Jian. The design and implementation of the residential property management system. Master thesis. East China Normal University, 2009

[3] Guo Feng. The design and implementation of the residential property intelligent management system. Master thesis. Harbin: Heilongjiang University, 2011

[4] Zhao Yu. Analysis and design of residential property management system. Master thesis. Ji'nan: Shandong University, 2009

[5] Li Shuang. The design and implementation of residential property management system. Undergraduate thesis, Shenyang: Shenyang Normal University, 2009

[6] Workflow Management Coalition.Workflow Client Application APIs (WAPI), WfMC-TC1009.2002

[7] Workflow Management Coalition. Workflow Interoperability Specifications, WfMC-TC-1012. 2002

[8] Yang Bin. The solution based on Web workflow management system. Journal of Northwestern University.1999:491-494 